\title{
Business Intelligence in the Database Marketing - A Case Study of a German Insurance Company
}

\author{
Claus-Peter H. Ernst \\ CBS International Business School \\ c.ernst@cbs.de
}

\author{
Frauke Amancio dos Santos \\ Frankfurt University of Applied Sciences \\ frauke.amancio@web.de
}

\begin{abstract}
We perform a case study in order to analyze the BI practices of the database marketing departments of insurance companies and hone in on the challenges they face. More specifically, we take a look at the database marketing department of one of the biggest German insurance companies by executing three guided expert interviews and enhancing the information gathered through a document analysis. Among our findings regarding the department's BI process are that the department collects customer data solely from internal sources and that the collected data is mainly analyzed through SQL queries. The department's greatest challenges involve including internal and external data sources that are currently not used in their analyses, gathering and understanding all the data that the company already has - since it is stored in different database tables and in heterogenous formats across the company - and measuring the success of their BI activities.
\end{abstract}

\section{Introduction}

Customers are a companies' central asset. Since it is more profitable for a company to improve their relationship with their existing customer base than to put a lot of effort into acquiring a new one [e.g., 1], keeping customers satisfied and, as a result, loyal [e.g., $2]$, is one of the most important tasks for companies.

However, satisfying customers is no easy task to accomplish. One strategy to gain a competitive advantage over other companies is getting to know exactly what the customers need and want. And since needs and wants can vary greatly between different customer groups, companies ideally need to be able to understand each customer individually [e.g., 3].

Analytical customer relationship management (CRM) transforms customer-related information within a company's databases into knowledge about them; a specific kind of analytical CRM called database marketing focuses on gaining knowledge about individual customers [e.g., 4]. In order to do so, they use "[b]usiness intelligence (BI) ...[, which] includes the applications, infrastructure and tools, and best practices that enable access to and analysis of information ..." [5]. Indeed, by applying BI to gather and analyze customer data, it is possible to create individual customer profiles that can be used for customer-specific approaches and offers [e.g., 6].

Although there is a large body of literature on BI's methods, tools, impact, success factors, etc., surprisingly little is known about how companies are actually drawing on BI in their day-to-day CRM. While there are studies that look into the application of BI in banks' CRM activities [e.g., 7, 8], no study that we are aware of deals specifically with the usage of BI in database marketing processes. Likewise, knowledge about insurance companies' BI practices in CRM is sparse, despite the fact that the companies strongly depend on data analyses in order to offer their highly complex and individual products.

This paper addresses these two identified gaps by studying the real-world practices of BI in the database marketing of insurance companies. More specifically, we seek to contribute to the following research question: How do insurance companies make use of BI in their database marketing and what challenges do they face?

In order to answer this question, we performed a qualitative, descriptive research approach in the form of a case study. The subject of the case study is one of the biggest German insurance companies. We executed three guided expert interviews with one executive manager as well as two employees - one in charge of data analysis and one in charge of reporting — and enhanced the case study with a document analysis.

The paper is structured as follows: First, we will give a short description of the insurance industry and emphasize its strong dependence on data. Next, we will elaborate on the theoretical background of analytical CRM, database marketing, and BI. Following this, we will describe the case study research methodology, our specific research design, how we collected our data, 
and how we analyzed it. Then we will present our findings. Finally, we conclude our article by discussing the study's results, its limitations as well its implications.

\section{Background}

\subsection{Insurance industry}

In general, the insurance industry is strongly datadriven. More specifically, it relies on the mathematical calculations of individuals' long-term risk probabilities. As a result, insurance industry products are highly complex and require a high level of consultation. The more insurance companies know about an individual customer, the more precisely they can calculate their individual risk probability and provide them with offers that coincide with their individual needs.

However, after the customers have signed their insurance contracts, they usually only contact the company later on when they are trying to claim damages and get their insurance coverage. As a result, insurance companies do not have regular contact points with their customers. Still, as digitalization extends its presence in all business processes, more customer data becomes available and thus enables insurance companies to collect and analyze it so that they can build a lasting and valuable relationship with their customers. This task is usually referred to as analytical customer relationship management (CRM) [e.g., 9] and the process of data analyses is commonly called business intelligence (BI) [e.g., 10]. In the following section, we will introduce both of these concepts.

\subsection{Analytical customer relationship management}

In general, CRM is defined as "an enterprise approach to understanding and influencing customer behavior through meaningful communications in order to improve customer acquisition, customer retention, customer loyalty, and customer profitability" [11, p. 12]. As a result, CRM ideally provides a win-win situation for customers and companies, with the former becoming more satisfied with the products and services offered and the latter becoming more profitable due to a loyal customer base.

CRM can be differentiated into various areas of expertise [e.g., 12]: operational CRM, cooperative CRM, and analytical CRM. Operational CRM contains all applications and tasks with direct customer contact such as call and support centers, the sales force, and social media marketing. The goal of cooperative CRM (sometimes also referred to as communicative CRM) is to reach and secure customers in collaboration with the distribution partners and, thus, includes the management of all sales channels as well as the cooperation with resellers and distribution partners. The goal of analytical CRM goal is the individualization of customer contact and offers. Therefore, it analyzes customer data in order to generate knowledge about them and to steadily improve all customer-related business processes.

One specific kind of analytical CRM is database marketing. It can be defined as a marketing strategy that focuses on individual customers, based on all the customer-related information stored in databases [4]. By generating knowledge about individual customers using BI [e.g., 13], database marketing helps to identify potential buyers for specific products, which can then be approached accordingly. Commonly, database marketing focuses on cross-selling (selling additional products to existing customers), upselling (selling a higher valued product to a customer that was initially interested in another lower value product), and preventing customer attrition.

\subsection{Business intelligence}

Generally, BI is used by companies to gain information from the vast amount of data available and to make more informed decisions based on the generated insights [11]. Usually, it consists of four interconnected steps, where each new step is built on the results of the previous steps: data collection, data integration and transformation, data analyses, and a final reporting of the insights gained.

In order to achieve high-quality knowledge, BI needs huge amounts of collected input data. The more datasets are available the more reliable the results will be [14]. Usually, this data comes from a variety of sources.

Therefore, it is heterogenous with regard to syntaxes, may have data conflicts, may include incomplete datasets, etc. The process of data integration and transformation (also called data warehousing) unifies the data's structure and stores it in a joined database. This, of course, also includes identifying and resolving data conflicts as well as recovering incomplete data, in order to make all data available and usable for the subsequent analyses. Generally, the step of data integration and transformation largely defines the quality of the analyses' outcomes [14].

For the subsequent data analyses, multiple methods from different areas of computer science are used: artificial intelligence, machine learning, database systems and statistics, to name a few [6]. Generally, 
tools using these methods enable practitioners to extract knowledge from their given datasets [e.g., 14].

Finally, the generated knowledge needs to be reported to all concerned entities. In order to accomplish that, it must be processed into a comprehensive and comprehensible form and usually needs to be customized to meet all the different stakeholders' requirements.

\section{Methodology}

\subsection{Case study}

In this paper, we want to contribute to the question of how insurance companies make use of BI in their database marketing, and what challenges they face. In order to do this, we chose a qualitative, descriptive research approach in the form of a case study, consisting of guided expert interviews that are enhanced through a document analysis [15].

In general, case studies are a research method that enables researchers to examine real-life phenomenon in their "natural setting[s], employing multiple methods of data collection [such as interviews, observations, document and text analysis] to gather information from one or a few entities ...' [16, p. 370], and these case studies are especially appropriate to deal with 'how' and 'why' questions [17]. Indeed, rather than simply holding an abstract theoretical view on a specific phenomenon, focusing on specific cases gives researchers the opportunity to gain a real-world perspective on it. Furthermore, descriptive case studies in particular enable researchers to conduct in-depth observation and analysis of a phenomenon, including its process and outcomes [17].

Expert interviews focus on gathering relevant data by interviewing an expert in the relevant field [e.g., 18]. Thus, the expertise and function of the respondents are the focus of the conducted interviews. Major themes regarding a certain topic may be identified more readily in the context of an interview, and the expertise of the interviewee can be used to enhance the research process [cf. 18]. Furthermore, the interviewer can examine relevant issues in greater depth based on the respondent's statements, and follow up on information during the interview. Usually, document analyses help the researcher further elaborate the statements of the interviewee, after the interview [17].

\subsection{Research design}

In order to gather relevant information to a research question, the interview guide is the key element and requires appropriate attention in order to highlight the central topics [19]. Given our research question, we structured our interview guide based on the four usual steps of BI described above: data collection, data integration and transformation, data analyses, and a final reporting of the insights gained.

The interview guide was designed to provide orientation during the interview and its questions were formulated in an open manner. Below, you will find an English translation of the original German questions in our interview guide. The guide also contained the standard parts of interviews such as an introduction of the participants [20].

- Data collection: What kind of data do you have? Where does it come from? Do you analyze historical data or real-time data? Do you use data solely from your contracts or also data from other sources? Do you see problems with regard to the availability of data?

- Data transformation: How and where is the data integrated? Does it need to be transformed and how? What challenges do you face?

- Data analyses: What analysis methods and programs are used? Do you analyze with specific insurance products in mind? What is the overall goal of your analyses? What are your results? Are the results as desired? Are there specific indicators or patterns for specific products? How long do specific analyses usually take? How often do you conduct typical analyses? Do you face any problems with regard to the analyses?

- Reporting: How are the analysis results prepared for the sales representatives? Do you also report findings to other departments and do they actively use them? How do you prepare the information for them? What challenges do you see?

\subsection{Data collection and analysis}

The subject of our case study is one of the biggest German insurance companies, with more than 5 million customers, over 20 million contracts, and more than 10 thousand employees. It offers a complete portfolio of insurance policies to its customers, ranging from property and casualty insurance, to health and life insurance, to retirement planning. It generally offers standard products to private customers, in order to secure them from the most common risks. For corporate clients, it usually offers customized products. Additionally, it also acts as a worldwide reinsurer. ${ }^{1}$

\footnotetext{
1 Due to a guarantee of anonymity, we will not provide further details that would allow to draw conclusions about the insurance company in focus.
} 
The most important task of the company's database marketing department is to support the field sales force. More specifically, the database marketing department helps the sales representatives by identifying sales opportunities and attrition risks within the existing customer base. It consists of nine employees.

First, we interviewed an executive manager of the company' database marketing department (who will be referred to as interviewee A) in May 2017. The interview was conducted in German at one of the company's German offices, lasted one hour and, with the consent of the interviewee, was recorded on tape and subsequently transcribed. The transcribed text was then analyzed by using the content analyses as described by Mayring [21], with methods such as deleting identical statements and joining connected arguments.

Additionally, two follow-up interviews were conducted in July 2017 with two employees of the database marketing department - one in charge of data analysis and one in charge of reporting (referred to as interviewees $\mathrm{B}$ and $\mathrm{C}$, respectively). The interviews lasted 45 and 47 minutes, respectively, and were also transcribed and subsequently analyzed using content analyses [21].

Finally, the database marketing department gave us access to their internal documents regarding its analyses and processes such as process descriptions, analyses files, and management reports.

\section{Findings}

\subsection{Data collection}

4.1.1. Internal data. Interviewee A explained that the database marketing team currently uses only internal data provided by the different departments of the company. This includes customers' core data (age, profession, etc.) and contract data (information concerning the insurance policies customers currently have or have had in the past, the date at which customers bought their first insurance policy, etc.). In order to store all this data, the company has a company-wide database system where all departments save their data into their respective tables. The database marketing team has access to all of the company's database tables to potentially use the data for analyses.

However, the database marketing department currently uses only general customer and contract data. For example, they may use data that specifies whether or not customer Smith currently has a car insurance policy. More revealing details such as whether the contract is a partial coverage insurance or a comprehensive insurance, whether it includes coverage for hail damages, or whether potential passengers are also covered, are not used.

Another source of internal data that is currently not used is the field sales force. Indeed, sales representatives have the most direct contact with customers. Although sales representatives collect important information about customers' life situations, needs, and service wishes, during their direct interactions with them, they only do so within their own physical or digital records. However, a project was set in motion to oblige sales representatives to store all the collected customer data in the central system.

Another kind of data that is currently collected but not used is the data from the company's call and service centers. More specifically, about 1.5 million calls are answered yearly and for each call, the employees make a short note that summarizes the call. However, this data is currently not used for any analyses.

Moreover, the company also gathers clickstream data from the company's websites. However, as A describes, the collected data is not deemed sufficient enough and is therefore not used in the analyses of the database marketing department at the moment.

4.1.2. Data from other distribution channels. In addition to the sales representatives, the case study's insurance company also uses further distribution channels such as partnerships with some banks. However, at the present time, there is no data exchange between these distribution partners and the insurance company. However, A described that having access, for example, to the customers payment flows and their transactions would be beneficial for database marketing and gave the example of a customer paying for a vacation. If the insurance company would know about this payment, it would enable the company to contact the customer and offer them a fitting vacation accident policy.

4.1.3. Data from external companies. Other potential sources of customers data are databases provided by external companies [e.g., 22]. Such databases provide sociodemographic data such as age, average number of children, and purchasing power, down to specific streets. Currently, the database marketing department does not use this information, but corresponding databases of other providers were evaluated and are currently taken into consideration in order to improve the data collection process in the future. 


\subsection{Data transformation}

Although the insurance company currently uses only internal data, this data still comes from various databases tables within the company. Since departments save their data in different structures and semantics, just having access is not enough for successful analyses. Interviewee A emphasizes that the database marketing department always needs to understand the meaning as well as the context of data in order to use it for analyses. Therefore, the data from different tables needs to be transformed in order to fit the intended analyses and the corresponding purposes.

In order to accomplish this transformation, B describes that all data is first mirrored into the database marketing department's own database tables. Then, the department specifies transformation rules that make sure that the imported data is usable and reliable for all subsequent steps. For example, there are rules in place on how missing values are handled (fill with 0 ) and how to code specific data ('customer is retired' $\rightarrow$ ' 8 '). Interviewee A emphasizes that a proper transformation has a huge impact on quality of the subsequent analyses. Hence, the database marketing team has to always keep up with any changes made within the other departments' data structures.

\subsection{Data analysis}

Interviewee A describes two central goals of the database marketing department's BI endeavors: increasing policy sales and reducing customer attrition. As a result, all current analyses are built to identify customers that may provide cross-selling or upselling opportunities (sales opportunities) as well as customers that are prone to attrition (attrition risks). At the moment, the insurance company creates 88 different categories of such opportunities and risks, respectively. In order to do so, it uses two analyses methods: structured query language (SQL) queries and data mining.

4.3.1. SQL queries. The majority of the sales opportunity and attrition risk categories are generated using SQL queries. Among other things, SQL queries can select data out of a database's tables based on specified criteria. The criteria that the insurance company uses are based on experience, usually focus on specific target groups, and are defined in cooperation with the product management team. When a new insurance product launches, criteria are chosen to narrow down the respective target group. For example, SQL queries may enable the department to select all customers that are 30 to 40 years old, have a car insurance, and do not currently have an accident insurance policy.

In other words, the company's current starting points are always the products it intends to sell. Based on a product's characteristics, database marketing tries to identify the customers that might be interested in this particular product. However, as A indicates, a current objective is to fundamentally change the process down the road by starting from the needs and wants of specific customers in order to identify the company's products that might be most interesting for those individuals.

According to $\mathrm{B}$, the database marketing department has built a software program that includes all predefined SQL queries. More specifically, for each opportunity and risk category, the corresponding queries are hardcoded into the software and no manual adjustments are needed to run the corresponding analyses.

For example, one sales opportunity category of the studied insurance company deals with the prolongation of a specific insurance product [internal document 1] $]^{2}$. The first query always filters certain customers out. For this, a criterion called customer value is used. More specifically, the company divides its customers into five customer segments: Segment one contains top customers that have the highest value, whereas segment five contains customers that have received due payment notices or have a high cancellation rate. Customers of segment five are always filtered out of the analyses, as the company is not interested in intensifying business with them. Additionally, the company also filters out its own employees as there are other sales channels specifically designed for them. Since the presented example sales category is for a prolongation, one specific query makes sure that only customers that actually have this kind of insurance product are selected. Additionally, the contract needs to have an annual net premium of at least $100 €$ and needs to expire within the next five to eight months. Whereas these are the main conditions for the sales opportunity at hand, more conditions are actually applied. Indeed, commonly about twenty to forty criteria are part of the selection process for each sales opportunity and attrition risk category.

In addition to the customer selection criteria, the software program also contains automatic quality control checks. More specifically, the program ensures that the data was properly mirrored into the departments database tables and also checks for data quality. If there are, for example, duplicates in the

\footnotetext{
${ }^{2}$ Due to the guarantee of anonymity, we will not provide details about the internal documents we used. We only numbered them to make them distinguishable.
} 
database, the program will give a warning about the issue. In addition to these automatic control mechanisms, $\mathrm{B}$ describes that there are additional manual spot-checks that are regularly performed by the database marketing team to further ensure the analyses' reliability.

Moreover, the department also needs to ensure that the analysis results are actually helpful to the sales representatives, so that they can better counsel customers. In order to ensure this, the department currently checks whether any changes occurred within the customers profile during a period of six months after a sales opportunity was identified. Any positive change such as the signing of a new contract will be counted as a success of their provided information, although the database marketing department cannot say with certainty that the positive change is actually based partly or entirely on their identified sales opportunity. However, A says that the department is aware of this problematic interpretation of customer profile changes and plans to improve the process by introducing more detailed and specific control mechanisms regarding the success of their BI practices in the future. In addition to the current automated success control mechanisms, A emphasized that the database marketing department also regularly talks to sales representatives as well as customers in order to get detailed feedback about whether or not its work is perceived as useful.

If at some point the department comes to the conclusion that a specific sales opportunity is no longer generating actual sales, the selection criteria are thoroughly reviewed and potentially adjusted. After some time and as a final consequence, the category will be taken out of service in order to free up its resources for potentially more prolific categories.

4.3.2. Data mining. Generally, data mining is a process of extracting, previously unknown knowledge from large datasets by discovering patterns, correlations, and anomalies [e.g., 14] using various areas of computer science [e.g., 6]. Interviewee A says that database marketing is conducting data mining through logistic regressions using the SAS Enterprise Miner software. Since the analysis is based on longterm attributes and does not take short-term transaction data into account, data mining is only conducted once per month. Currently, data mining is exclusively used to generate sales opportunities, although $\mathrm{C}$ indicates that their approach could also be used to forecast customer attrition.

At the beginning of the process, the database marketing department, in cooperation with the product management department, chooses specific products to do sales forecasts for. However, not all products are suitable for purchase forecast analysis since data mining typically requires large amounts of historic data as a learning set. As a result, only products that are sold for at least twelve months and have reasonable amounts of signed contracts are usable. According to $\mathrm{C}$, this is one reason why only few sales opportunity categories are actually based on data mining. Indeed, A states that only about 17 categories out of the overall provided 88 categories are currently generated via data mining.

$\mathrm{C}$ specifies that the historic data of the product being analyzed always acts as the starting point of the data mining process. The historic data is always based on all customers and covers the past twelve plus two months so that the database is broad and the seasonal effects on the product's sales performance are taken into account. Logistic regression uses the historic data as a training set in order to "learn" which attributes and attribute combinations lead to, or do not lead to, the purchase of the product in question. Based on the results, SAS Enterprise Miner outputs a score for each customer that predicts their likeliness to purchase the specific product. More specifically, it creates a score between 0 and 1 with 1 describing a customer that is expected to be highly likely to buy the product. The 20 percent of customers with the highest score are defined as high affinity customers and their corresponding data is later given to the sales representatives, so they can contact them. The other 80 percent of customers are used for control purposes. More specifically, database marketing tracks which customers purchased the product in question and compares the rate of signed contracts between the 20 and 80 percent groups, in order to make sure that most policies were actually bought by the customers forecasted to have a high product affinity. According to $\mathrm{C}$, the logistic regression model proved to be very stable in generating high quality purchase forecasts.

Interviewee A also described the intended future applications of data mining. Similar to their vision for SQL queries, database marketing wants to use data mining to predict individual customers' current or upcoming needs. However, according to A, more detailed customer and contract data will be needed in order to achieve this goal. Given the limited resources of the department, he believes that it will prove difficult to access and prepare all the necessary additional data sources and to find a sufficiently lengthy trial-and-error period in order to identify helpful correlations within the data.

\subsection{Reporting}

4.4.1. Sales opportunities and attrition risks. As described above, the field sales force receives the customer insights generated by the database marketing 
department through sales opportunities and attrition risks. Each sales representative only receives the opportunities and risks for their assigned region [internal document 2].

In order to obtain this information, sales representatives have to sign up for the specific opportunity and risk categories they are interested in, using a Microsoft Outlook form. Within this form, they can also define the maximum number of datasets they want to receive as well as choose whether the datasets should be sent to them one time only or on a weekly basis. Since the sales opportunities and attrition risks are strictly based on products, it can happen that no customer in a sales representative's region fulfills the selection criteria at a given time, resulting in no datasets being sent out.

For a given week, the sales representatives need to fill out the form by Wednesday midnight, since all analyses are performed every Thursday at 4 am and are sent out as soon as they are completed. The datasets are delivered to the sales representatives via e-mail; the emails either contain a pdf document only or a pdf document together with an excel sheet, respectively, based on the sales representatives' preferences. B specified that all regional managers also receive accumulated summaries of the sales opportunities and attrition risks that are sent out to sales representatives within their respective region. After receiving the information, the sales representatives can then contact the corresponding customers and may afterwards provide feedback to their respective regional manager [internal document 3].

As B describes, each sales opportunities and attrition risks report contains three types of content: The first page provides an overview of all the sales opportunity and attrition risk categories a sales representative has asked for, along with the corresponding number of identified customers for each of these categories. The second page provides a summary of the overall potential in their customer base, i.e., the potential in all available categories, including those that were not requested. Finally, the individual sales indications and attrition risks are provided. Finally, each individual opportunity and risk includes the personal information of the customer (such as name, date of birth, profession) as well as information about the sales representative (such as their name, the region they operate in, their agency number). Furthermore, it includes information on the specific sales opportunity or attrition risk category: for example, the name of the category, the customer's contracts that are important for the category, the annual net premium for each of the customer's contracts, and all the contracts that were cancelled by the customer during the last 24 months. Moreover, there is also information about the customer's purchase history such as the date the customer signed their first contract, the date they signed their last contract, and their customer value status. Additionally, it provides information about other sales opportunity and attrition risk categories that might be relevant to the specific customer, although the sales representative might not have asked for information about these respective categories. This information is provided in order to enable the representative to comprehensively counsel the given customer.

The sales representatives are also given guidance and recommendations for action, such as recommendations to perform an up-to-date risk-andneed analysis if the contract was signed more than three years ago. Additional information is given concerning the timeframe during which the customer will be excluded from further analyses. More specifically, when a sales representative receives information about a customer in the aforementioned way, this customer will be blocked for six months from analyses for most sales opportunity and attrition risk categories. According to A, this is done to not overload the customer with counseling appointments and offers within short periods of time. However, $\mathrm{C}$ points out that some important categories, such as those that deal with high-value and time-sensitive matters (which corresponds to 19 categories), are still sent out during the blocking period. One such category is an indication to prevent the cancellation of a life insurance.

In addition to the sales representatives, employees of other distribution partners can also request sales opportunity and attrition risk categories. However, they cannot do so directly; rather, they have to go through the insurance company's corresponding regional manager. However, they can only request about 15 of the 88 categories, which are generally categories that require less counseling such as forecasts with regard to private liability insurances [internal document 2].

4.4.2. Sales potential report for distribution partners. Another report that the database marketing provides for other distribution channels such as banks is the sales potential report. This report is available to all regional managers and contains information about the existing customer base in the region as well as market potentials [internal document 4].

More specifically, the report contains detailed information about the insurance company's customers that are also customers of the distribution partner and those of the region that are not. The report further provides information about the purchasing power in the region and analyzes the customer potential.

According to $\mathrm{C}$, the report needs to be ordered by the regional managers repeatedly. The report enables 
them to discuss specific joint actions that are a common interest for both the insurance company and the distribution partner. As B points out, the easy access to potential new customers is beneficial to the insurance company, and the distribution partner increases the satisfaction of their customer base by being able to offer them integrated counseling that covers all their needs.

4.4.3 Management report. On an annual basis, the database marketing department summarizes and presents all the information about their customers' development in the form of a management report. It presents corresponding information at a high level but also drills down selectively to provide insights on specific regions, sales channels, and product categories. The information that is covered is, for example, customers' average age, the average duration of customer relationships, and the average amount of contracts that a single customer has in specific regions. Furthermore, the report quantifies the success of the different marketing actions such as the success of identified sales opportunities [internal document 4].

\section{Conclusion}

In this article, we did a case study in order to take a look at the BI practices of the database marketing department of a German insurance company and the challenges it faces. We found out that the department collects customer data solely from internal sources. After the transformation and warehousing of the heterogenous data of different departments and their individual databases, the data is then analyzed, mainly through SQL queries and only to some degree using data mining via logistic regression. The generated sales opportunity and attrition risk categories are then provided to the sales representatives, regional managers as well as other distribution partners in order to enable them to improve their relationships with existing customers and to offer them products that might be of interest to them.

Our case study revealed that the biggest challenge for the insurance company's database marketing department is the availability of relevant data. Currently, there is a large unused data potential within the company, such as the information that is provided by customers to sales representatives during the consultations, which is not stored in the central system but is only present in the localized physical or digital records of the sales representatives. Moreover, the department also faces challenges while gathering and understanding the data the company already has, which is stored in different database tables, and presented in heterogenous data structures across the company's different departments. The database marketing is aware of the fact that more detailed data, especially with regard to data mining analyses, can provide more specific insights on the how and why customers choose specific products. However, the team struggles with the lack of resources with regard to time and money, which hinders it from using the full potential of the existing data and from exploiting additional data sources.

Another central challenge for the database marketing department is the evaluation of the success of its BI activities. Currently, success is only measured for identified sales opportunities and is based on the number of contracts a customer signs during the six months after their data was provided to a sales representative, without taking into account whether they were even contacted by a sales representative during that timeframe or whether the identified sales opportunity was even about those new contracts.

In the future, the database marketing department will try to face its challenges and to continue to steadily improve their analyses results in order to improve customer relationships, satisfaction, and loyalty. Indeed, the company plans to move to a new strategy with one key aspect being to put customers and their specific needs and wants at the center of the analyses. For example, the database marketing department plans to allow sales representatives to request opportunity and risk categories for specific customers they might connect with in the near future. This enables them to recommend potentially relevant products to the customer, and to avoid potential attrition.

Our study has some limitations. Our findings are largely based on three expert interviews with employees of one German insurance company. Generally, interviews as sources have limitations due to the nature of self-reported data [e.g., 18]. Indeed, researchers only get the information that the interviewee remembers provide, which is therefore limited by selective memory. In addition, the interviewees can have biased opinions, exaggerate certain aspects, and leave out certain information. However, in order to diminish these limitations, we also included internal documents such as process documentations into our case study. More specifically, these sources were used to back up and verify the information gained during the interviewees.

As we only took a look at one specific insurance company, our findings do not enable us to draw meaningful conclusions about other insurance companies or to make generalizations. In particular, there might be differences between German insurance companies as well as those from other countries and with different cultural backgrounds. As a result, further 
investigations appear necessary in order to be able to gain a comprehensive understanding about the application of BI in database marketing in general, and in insurance companies in particular.

Finally, BI is a fast-moving method that constantly evolves. As a result, case studies can only provide a snapshot in time about companies' corresponding practices.

Still, the findings of this work represent a first practice-based insight into the usage of BI in database marketing in the context of insurance companies and identifies current challenges of this specific industry. As a result, it provides both researchers and practitioners with starting points to help them leverage BI's full potential in this data-driven industry. Furthermore, it also provides a point of comparison for future empirical studies as well as a benchmark for other companies' BI activities and projects.

As a next step, and in order to address the limitations of this study, we plan to conduct more indepth case studies. More specifically, we plan to take a look at a greater number of insurance companies of differing sizes and from multiple countries in order to gain a broader understanding of their current BI practices in the context of database marketing, while also identifying possible cultural or size-based differences.

\section{References}

[1] R.W.T. Buchanan, and C.S. Gillies, " Value Managed Relationships: The Key to Customer Retention and Profitability", European Management Journal 8 (4), 1990, pp. 523-526.

[2] J.T. Bowen, and S.-L. Chen, "The Relationship between Customer Loyalty and Customer Satisfaction", International Journal of Contemporary Hospitality Management 13 (5), 2001, pp. 213-217.

[3] I.J. Chen, and K. Popovich, "Understanding Customer Relationship Management (CRM): People, Process and Technology", Business Process Management Journal 9 (5), 2003, pp. 672-688.

[4] P.C. Mandal, "Customer Databases and Database Marketing: Roles in Relationship Marketing", International Journal of Business Forecasting and Marketing Intelligence 3 (3), 2017, pp. 327-336.

[5] Gartner, Business Intelligence (BI), http://www.gartner.c om/it-glossary/business-intelligence-bi, 2019 (Accessed: 2020-09-23).

[6] C.-W. Chang, C.-T. Lin, and L.-Q. Wang, "Mining the Text Information to Optimizing the Customer
Relationship Management", Expert Systems with Applications 36 (2.1), 2009, pp. 1433-1443.

[7] N. Bekmamedova, and G. Shanks, "Social Media Analytics and Business Value: A Theoretical Framework and Case Study", HICSS 2014 Proceedings, pp. 3728-3737.

[8] S. Salehi, M. Kheyrmand, and H. Faraghian, "Evaluation of the Effects of E-Crm on Customer Loyalty (Case Study: Esfahan Branch's of Sepah Bank)", ECDC 2015 Proceedings.

[9] M. Xu, and J. Walton, "Gaining Customer Knowledge through Analytical CRM", Industrial Management \& Data Systems 105 (7), 2005, pp. 955-971.

[10] S. Negash, "Business Intelligence", Communications of the Association for Information Systems 13 2004, pp. 177-195.

[11] R.S. Swift, Accelerating Customer Relationships: Using Crm and Relationship Technologies, Prentice Hall, Upper Saddle River, NJ, 2001.

[12] F. Arab, H. Selamat, and M. Zamani, "An Overview of Success Factors for CRM", IEEE ICIFE 2010 Proceedings, pp. 702-705.

[13] E. Duman, Y. Ekinci, and A. Tanrıverdi, "Comparing Alternative Classifiers for Database Marketing: The Case of Imbalanced Datasets", Expert Systems with Applications 39 (1), 2012, pp. 48-53.

[14] J. Han, M. Kamber, and J. Pei, Data Mining: Concepts and Techniques, Morgan Kaufmann, Waltham, MA, 2012.

[15] M.B. Miles, and A.M. Huberman, Qualitative Data Analysis. An Expanded Sourcebook, Sage, Thousand Oaks, CA, 1994.

[16] I. Benbasat, D.K. Goldstein, and M. Mead, "The Case Research Strategy in Studies of Information System", MIS Quarterly 11 (3), 1987, pp. 369-386.

[17] R. Yin, Case Study Research: Design and Methods, Sage Publications, London, UK, 2002.

[18] A. Bogner, B. Littig, and W. Menz, Introduction: Expert Interviews - an Introduction to a New Methodological Debate, in A. Bogner, B. Littig and W. Menz (eds.), Interviewing Experts, Palgrave Macmillan, London, UK, pp. 1-13.

[19] H.O. Mayer, Interview und schriftliche Befragung: Entwicklung, Durchführung und Auswertung, Oldenbourg, München, Germany, 2008.

[20] C. Helfferich, Die Qualität qualitativer Daten. Manual für die Durchführung qualitativer Interviews, Springer VS, Wiesbaden, DE, 2005.

[21] P. Mayring, Qualitative Inhaltsanalyse. Grundlagen und Techniken, Beltz, Weinheim, DE, 2008.

[22] Deutsche Post Direkt, Gut zu wissen, wer ihre Kunden sind, http://www.deutschepost.de/de/d/deutsche-post-dir ekt/microdialog.html, 2019 (Accessed: 2020-09-23). 